\title{
The Potential of Biomaterial-Based Approaches as Therapies for Ischemic Stroke: A Systematic Review and Meta-Analysis of Pre-clinical Studies
}

\author{
Faye Bolan ${ }^{1 \dagger}$, Irene Louca ${ }^{1 \dagger}$, Calvin Heal ${ }^{2}$ and Catriona J. Cunningham ${ }^{1 *}$ \\ ${ }^{1}$ Division of Neuroscience and Experimental Psychology, Faculty of Biology, Medicine and Health, School of Biological \\ Sciences, University of Manchester, Manchester, United Kingdom, ${ }^{2}$ Faculty of Biology, Medicine and Health, Centre for \\ Biostatistics, Academic Health Sciences Centre, University of Manchester, Manchester, United Kingdom
}

OPEN ACCESS

Edited by:

Johannes Boltze,

University of Warwick,

United Kingdom

Reviewed by:

Claire Gibson,

University of Nottingham

United Kingdom

Jialing Liu,

University of California, San Francisco,

United States

*Correspondence:

Catriona J. Cunningham

catriona.cunningham@

manchester.ac.uk

tThese authors have contributed equally to this work

Specialty section:

This article was submitted to

Stroke,

a section of the journal

Frontiers in Neurology

Received: 29 March 2019

Accepted: 09 August 2019

Published: 27 August 2019

Citation:

Bolan F, Louca I, Heal C and Cunningham CJ (2019) The Potential of Biomaterial-Based Approaches as

Therapies for Ischemic Stroke: A Systematic Review and Meta-Analysis of Pre-clinical Studies.

Front. Neurol. 10:924

doi: 10.3389/fneur.2019.00924
Background: In recent years pre-clinical stroke research has shown increased interest in the development of biomaterial-based therapies to promote tissue repair and functional recovery. Such strategies utilize biomaterials as structural support for tissue regeneration or as delivery vehicles for therapeutic agents. While a range of biomaterials have been tested in stroke models, currently no overview is available for evaluating the benefit of these approaches. We therefore performed a systematic review and meta-analysis of studies investigating the use of biomaterials for the treatment of stroke in experimental animal models.

Methods: Studies were identified by searching electronic databases (PubMed, Web of Science) and reference lists of relevant review articles. Studies reporting lesion volume and/or neurological score were included. Standardized mean difference (SMD) and 95\% confidence intervals were calculated using DerSimonian and Laird random effects. Study quality and risk of bias was assessed using the CAMARADES checklist. Publication bias was visualized by funnel plots followed by trim and fill analysis of missing publications.

Results: A total of 66 publications were included in the systematic review, of which 44 (86 comparisons) were assessed in the meta-analysis. Overall, biomaterial-based interventions improved both lesion volume (SMD: $-2.98,95 \% \mathrm{Cl}$ : $-3.48,-2.48$ ) and neurological score (SMD: $-2.3,95 \% \mathrm{Cl}$ : $-2.85,-1.76)$. The median score on the CAMARADES checklist was 5.5/10 (IQR 4.25-6). Funnel plots of lesion volume and neurological score data revealed pronounced asymmetry and publication bias. Additionally, trim and fill analysis estimated 19 "missing" studies for the lesion volume outcome adjusting the effect size to -1.91 (95\% Cl: $-2.44,-1.38)$.

Conclusions: Biomaterials including scaffolds and particles exerted a positive effect on histological and neurological outcomes in pre-clinical stroke models. However, heterogeneity in the field, publication bias and study quality scores which may be another source of bias call for standardization of outcome measures and improved study reporting.

Keywords: systematic review, meta-analysis, stroke, biomaterials, tissue engineering, hydrogels, nanoparticles, regenerative medicine 


\section{INTRODUCTION}

Stroke is a global health problem with limited treatment options. The World Health Organization reports stroke as the second leading cause of death worldwide accounting for around 6.7 million deaths annually (1). For patients surviving stroke, close to two thirds will have a disability (2). Despite the major societal impact, the only widely available therapy for ischaemic stroke is tissue plasminogen activator (tPA). However, due to the narrow time window of administration ( $<4.5 \mathrm{~h}$ of symptom onset), only around $12 \%$ of patients in the UK are eligible for treatment (3). In recent years, great advances have been made in the development of endovascular thrombectomy as an alternative treatment (4, 5). While clinical trials have demonstrated thrombectomy is effective up to $6 \mathrm{~h}$ after stroke onset, it has been estimated that only $10 \%$ of patients would be eligible even with national coverage in the UK, which is presently not the case (6). Both thrombolysis and thrombectomy aim to restore reperfusion and limit further damage to the ischaemic brain and there are currently no approved regenerative medicine therapies available for promoting repair and regeneration.

In recent years, interest in regenerative medicine approaches to increase neuronal tissue repair following ischaemic stroke has increased. Notably, over 20 early phase clinical trials have been conducted assessing the safety of cell therapies including mesenchymal stem cells (MSCs) (7), neural stem cells (NSCs) (8), and haematopoietic stem cells (9). A number of studies have used cell-based therapies and growth factors to promote endogenous brain repair or tissue replacement in animal models of stroke with limited success. For this reason, biomaterials are now being investigated as potential agents to enhance the therapeutic efficacy of such interventions as scaffolds for tissue regeneration or vehicles for drug release $(10,11)$. For example, cell transplantation in the brain may be facilitated by the use of engineered scaffolds, which mimic native extracellular matrix (ECM) properties and provide adhesion sites for native cell attachment, aiding graft cell retention in the infarct cavity $(12,13)$. Alternatively, scaffolds may be used to aid recruitment and survival of endogenous stem cell populations for tissue restoration. Examples of scaffolds studied for cell delivery in stroke models include natural and synthetic hydrogels, electrospun fibers, sponges, and glue. Particulates are another class of biomaterials commonly used as delivery systems for targeted and controlled release of therapeutic agents. A wide variety of particulates have been tested for ischaemic stroke repair including nanoparticles, microparticles, micelles, liposomes, nanocarriers, and microspheres $(14,15)$.

To date, there is no systematic review or meta-analysis available investigating the potential of biomaterial-based approaches in pre-clinical models of ischaemic stroke. Given that biomaterial-based interventions are currently attracting great interest it is timely therefore to provide such a review, with the hope of averting the "translational roadblock" (16) and poor predictive validity of previous studies of neuroprotective agents for stroke $(17,18)$. Our systematic review and meta-analysis aims to assess the methodological quality of current research into biomaterial-based interventions for ischaemic stroke repair and to determine the efficacy of such approaches, helping to inform future research directions.

\section{MATERIALS AND METHODS}

\section{Search Strategy}

We searched PubMed and Web of Science for (stroke OR cerebral ischemia OR cerebral ischemia) AND (biomaterial OR tissue engineering OR hydrogel\$ OR scaffold $\$$ OR * particle $\$$ OR sponge\$). No restrictions were placed on date of publication and the last search was conducted on 4 February 2019. We also searched reference lists of review articles for additional articles. Titles and abstracts were initially screened by two authors (CC and FB).

\section{Data Sources, Studies Selections, and Data Extraction}

Full texts of the identified publications were screened (CC, FB, and IL) for studies assessing the efficacy of biomaterialbased strategies in pre-clinical models of cerebral ischemia. Studies were included if lesion volume and/or neurological score were reported as outcome measures. Studies in which the method of induction of cerebral ischemia was not stated were excluded. After screening full texts for suitability, study design information was extracted from each publication (CC and $\mathrm{FB}$ ). Information extracted included the species and stroke model used, type of biomaterial investigated and whether the material was combined with another therapeutic agent (such as growth factors or a drug), the time of administration and any functional tests conducted.

The risk of bias of each publication was assessed using the CAMARADES (Collaborative Approach to Meta-analysis and Review of Animal Data in Experimental Studies) study quality checklist (19): (1) peer reviewed publication; (2) control of temperature; (3) random allocation to treatment or control; (4) blinded induction of ischemia; (5) blinded assessment of outcome; (6) use of anesthetic without significant intrinsic neuroprotective activity; (7) animal model (aged, diabetic, or hypertensive); (8) sample size calculation; (9) compliance with animal welfare regulations; and (10) statement of potential conflict of interests. All information extracted was independently cross-checked by a second reviewer (CC, FB, and IL).

For both lesion volume and neurological score, mean values, \pm standard deviation (SD) or standard error of the mean (SEM), and group sizes for treatment and control groups were extracted. Publications that did not specify specific group sizes and reported variance as SEM or did not include control groups were excluded from the meta-analysis. Where variance was reported as SEM, this was converted to SD in Microsoft Excel in order to calculate standardized mean difference (SMD) for analysis. Since the effect of biomaterial administration on stroke recovery was the main focus of this analysis, control groups chosen for comparisons were either stroke only or vehicle. In cases where the material was combined with additional therapeutic agents, stroke or vehicle were also used as controls. In two cases $(20,21)$, the control 
group was biomaterial alone so these papers were excluded from the meta-analysis.

Two publications which presented lesion volumes and neurological scores as median \pm interquartile range (IQR), were also excluded from the meta-analysis $(22,23)$. One paper expressed the neurological score inversely to the convention (higher scores indicate a higher degree of impairment) so the data were inverted relative to the stated baseline measure (24). Where multiple treatments were assessed, we selected the treatment identified by authors in the publications as the primary focus. When publications reported multiple outcome measures from multiple timepoints, the data for the final end point was chosen. Where publications included multiple administration timepoints, data from each group was extracted separately.
Where possible, raw values were extracted from the text of the publication. When data was presented only graphically, the online tool WebPlotDigitizer (https://automeris.io/ WebPlotDigitizer/) was used to estimate mean and variance from graphs. Estimate measures were independently cross-checked by a second reviewer and any conflicts ( $>10 \%$ difference) were resolved by a third reviewer (CC, FB, and IL). For analysis of effect size, the publications were split into subgroups by type of biomaterial (scaffolds and particles). The scaffolds subgroup included publications using hydrogels, extracellular matrix scaffolds, fibrin glue, and sponges. The particles subgroup included publications using nanoparticles, microparticles, nanocarriers, microspheres, liposomes, nanoemulsions, nanotubes, and micelles. The selected publications were also

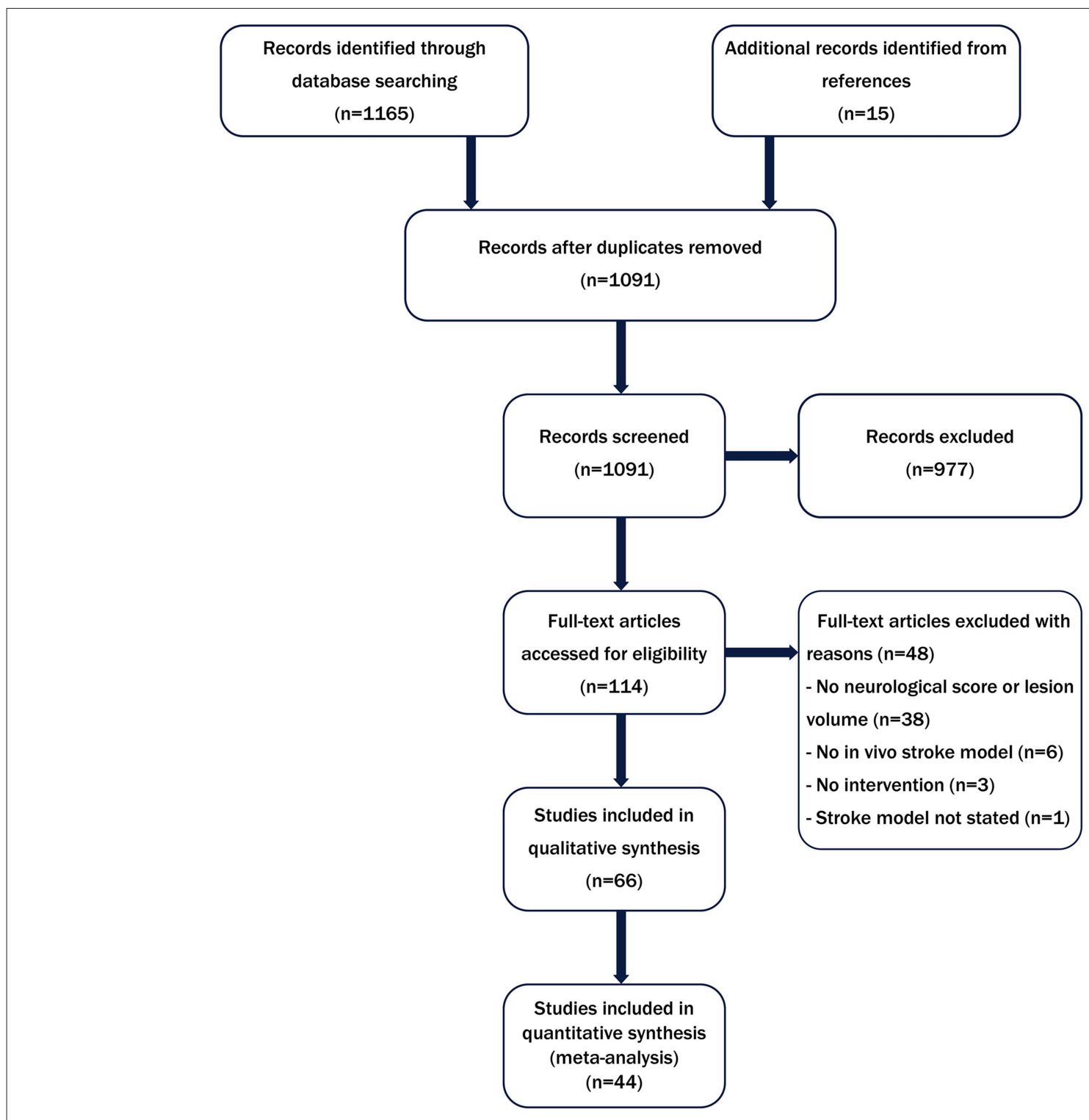

FIGURE 1 | Flow diagram summarizing the literature search strategy and number of studies included in the systematic review and meta-analysis. 
divided into subgroups according to the time of administration. The groups were as follows: administration prior to stroke and up to time of reperfusion; from reperfusion to $24 \mathrm{~h}$ post-stroke; $>24$ h to 1 week post-stroke; >1-3 weeks post-stroke and multiple administrations spanning these timepoints.

\section{Statistical Analysis}

For both the lesion volume and neurological score outcomes, the SMD between the trial arms and accompanying 95\% confidence intervals were calculated using DerSimonian and Laird random effects meta-analysis. Studies were weighted based on animal number. The presence of heterogeneity in the data sets was assessed using the $I^{2}$ statistic. Due to very high heterogeneity in the data $\left(I^{2}=82.8\right.$ and $84.3 \%$ for lesion volume and neurological score, respectively), random effects were chosen. Forest plots were used to visually present the results. The analysis was stratified by type of biomaterial and time of administration although for brevity, only the former are presented graphically. The extent of publication bias was assessed graphically using funnel plots and confirmed with Egger's regression test. The trim and fill approach was also used to estimate an effect size accounting for publication bias. Stata 15 (StataCorp, USA) was used for all statistical analyses with the exception of the trim and fill analysis which was conducted in RStudio version 1.1.463 (RStudio Inc., USA) using the metafor package (http://www. metafor-project.org/doku.php).

\section{RESULTS}

\section{Study Selection and Characteristics}

As shown in Figure 1, 1,091 publications were identified from our literature search of which 66 met the inclusion

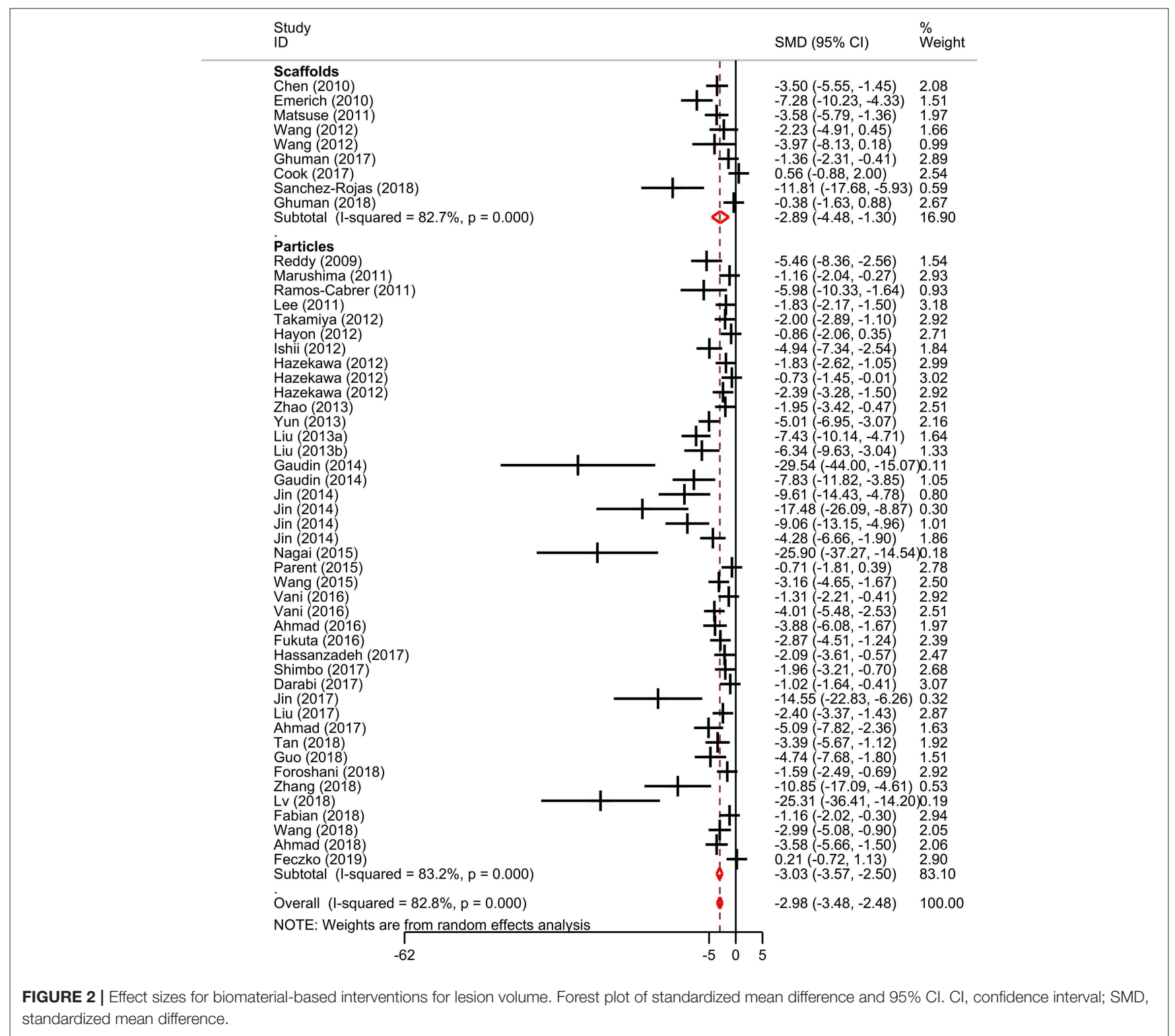


criteria for the systematic review. The characteristics of these studies including stroke model, animal numbers and type of biomaterial intervention are shown in Supplementary Table 1. All of the included studies were conducted in rats $(n=49)$ or mice $(n=16)$ or both rats and mice $(n=1)$. The most commonly used model was the transient intraluminal filament model of middle cerebral artery occlusion $(\mathrm{MCAO})(n=46)$. Only two studies used comorbid animals. Hayon et al. (25) used spontaneously hypertensive rats and Fabian et al. (26) induced acute hyperglycemia in Sprague-Dawley rats using streptozotocin. As shown in Supplementary Table 1, there was high variation in the functional outcome measures employed (23 different behavioral tests). Furthermore, several different neurological scores were reported including modified neurological severity score (both 14 and 18 points), Bederson, modified Bederson and Longa (27, 28). A total of 44 studies including 1,075 animals (control $n=522$, treatment $n=553$ ) were then included in the metaanalysis reporting 86 comparisons. Of these, 51 assessed lesion volume and 35 assessed neurological score. There was

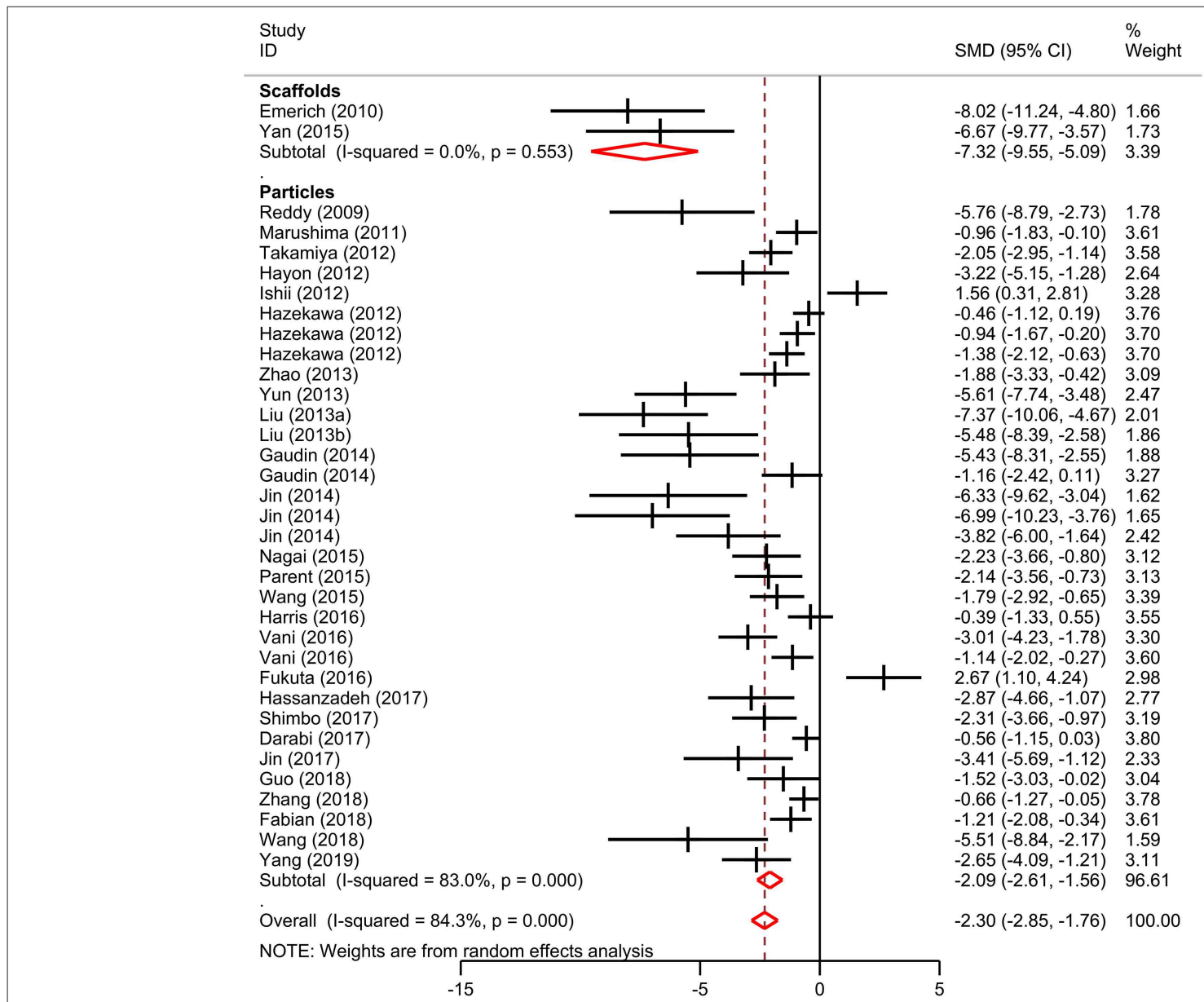

FIGURE 3 | Effect size for biomaterial-based interventions for neurological score. Forest plot of mean standard difference and 95\% Cl. Cl, confidence interval; SMD, standardized mean difference.

TABLE 1 | Subgroup meta-analysis comparing time of intervention on lesion volume and neurological score outcomes.

\begin{tabular}{|c|c|c|c|c|c|c|}
\hline \multirow[b]{2}{*}{ Time of intervention } & \multicolumn{3}{|c|}{ Lesion volume } & \multicolumn{3}{|c|}{ Neurological score } \\
\hline & Comparisons & Effect size $(95 \% \mathrm{Cl})$ & $I^{2}, p$-value & Comparisons & Effect size $(95 \% \mathrm{Cl})$ & $I^{2}, p$-value \\
\hline Pre-treatment-0 h & 25 & $-3.15(-3.76,-2.55)$ & $79.7 \%,<0.001$ & 18 & $-3.03(-4.10,-1.96)$ & $89.2 \%,<0.001$ \\
\hline$>0-24 h$ & 15 & $-3.94(-5.19,-2.69)$ & $87.1 \%,<0.001$ & 13 & $-1.84(-2.48,-1.21)$ & $75.3 \%,<0.001$ \\
\hline$>24 \mathrm{~h}-1$ week & 5 & $-2.15(-4.43,-0.14)$ & $85.5 \%, 0<001$ & 0 & $\mathrm{~N} / \mathrm{A}$ & $\mathrm{N} / \mathrm{A}$ \\
\hline$>1-3$ weeks & 3 & $-1.14(-2.27,-0.00)$ & $41.1 \%, 0.183$ & 0 & N/A & $\mathrm{N} / \mathrm{A}$ \\
\hline Multiple timepoints & 3 & $-3.51(-6.75,0.27)$ & $78.5 \%, 0.010$ & 4 & $-1.32(-2.18,-0.45)$ & $56.5 \%, 0.075$ \\
\hline
\end{tabular}


TABLE 2 | Summary of study quality assessed by study compliance to the CAMARADES risk of bias checklist.

\begin{tabular}{|c|c|c|c|}
\hline & Overall & Scaffolds & Particles \\
\hline (1) Peer-reviewed publication (\%) & 100 & 100 & 100 \\
\hline (2) Control of temperature (\%) & 50 & 42.1 & 53.2 \\
\hline (3) Random allocation to treatment or control (\%) & 56.1 & 52.6 & 57.4 \\
\hline (4) Blinded induction of ischemia (\%) & 34.9 & 42.1 & 31.9 \\
\hline (5) Blinded assessment of outcome (\%) & 50 & 52.6 & 48.9 \\
\hline (6) Use of anesthetic without significant intrinsic neuroprotective activity (\%) & 83.3 & 89.5 & 80.9 \\
\hline (7) Animal model (aged, diabetic, or hypertensive) (\%) & 3 & 0 & 4.26 \\
\hline (8) Sample size calculation (\%) & 9.1 & 15.8 & 6.4 \\
\hline (9) Compliance with animal welfare regulations (\%) & 93.9 & 89.5 & 95.7 \\
\hline (10) Statement of potential conflict of interests (\%) & 62.1 & 73.7 & 57.4 \\
\hline Median quality (/10) (IQR) & $5.5(4.25-6)$ & $6(4-7)$ & $5(4-6)$ \\
\hline
\end{tabular}

substantial heterogeneity in the datasets from both lesion volume and neurological score outcomes $\left(I^{2}=82.8\right.$ and $84.3 \%$, respectively).

\section{Synthesized Findings}

Meta-analysis was performed on lesion volume and neurological score data. Overall, treatment with biomaterial-based interventions led to improvements in lesion volume (SMD: $-2.98,95 \%$ CI: $-3.48,-2.48$ ). Both the scaffolds (SMD: $-2.89,95 \% \mathrm{CI}:-4.48,-1.30)$ and particles subgroups (SMD: $-3.03,95 \%$ CI: $-3.57,-2.50$ ) had comparable effect sizes (Figure 2). There was high variability in the reported effect sizes in the particles groups ranging from -29.54 to -0.21 . Similarly, biomaterial-based approaches were also associated with overall improvements in neurological score (SMD: -2.3 , 95\% CI: $-2.85,-1.76$; Figure 3). Administration of the biomaterial-based therapies within $24 \mathrm{~h}$ of stroke onset appeared to be most effective leading to the most marked improvement in lesion volume (SMD: -3.94, 95\% CI: $-5.19,-2.69$; Table 1).

\section{Risk of Bias and Study Quality}

Risk of bias was assessed using the CAMARADES checklist (19). Overall, the median score was 5.5/10 (IQR 4.25-6). Studies within the scaffolds (6/10, IQR 4-7) and particles (5/10, IQR 4-6) subgroups had very similar scores (Table 2). Reporting of randomization (56\%), blinding (35\% to stroke and 50\% to outcome) and sample size calculations (9\%) was low.

Publication bias was then assessed. From visual inspection of the funnel plot for lesion volume (Figure 4), there was pronounced asymmetry denoting publication bias. This was confirmed by Egger's regression test $(p<0.001)$. Similarly, there was asymmetry in the funnel plot of neurological score $(p<$ 0.001; Figure 4). Trim and fill analysis estimated 19 "missing" studies on the right side of the funnel plot of lesion volume outcome (Figure 5) which adjusted the effect size to $-1.91(95 \%$ CI: $-2.44,-1.38)$. Conversely, trim and fill analysis did not report any "missing" studies for neurological score.

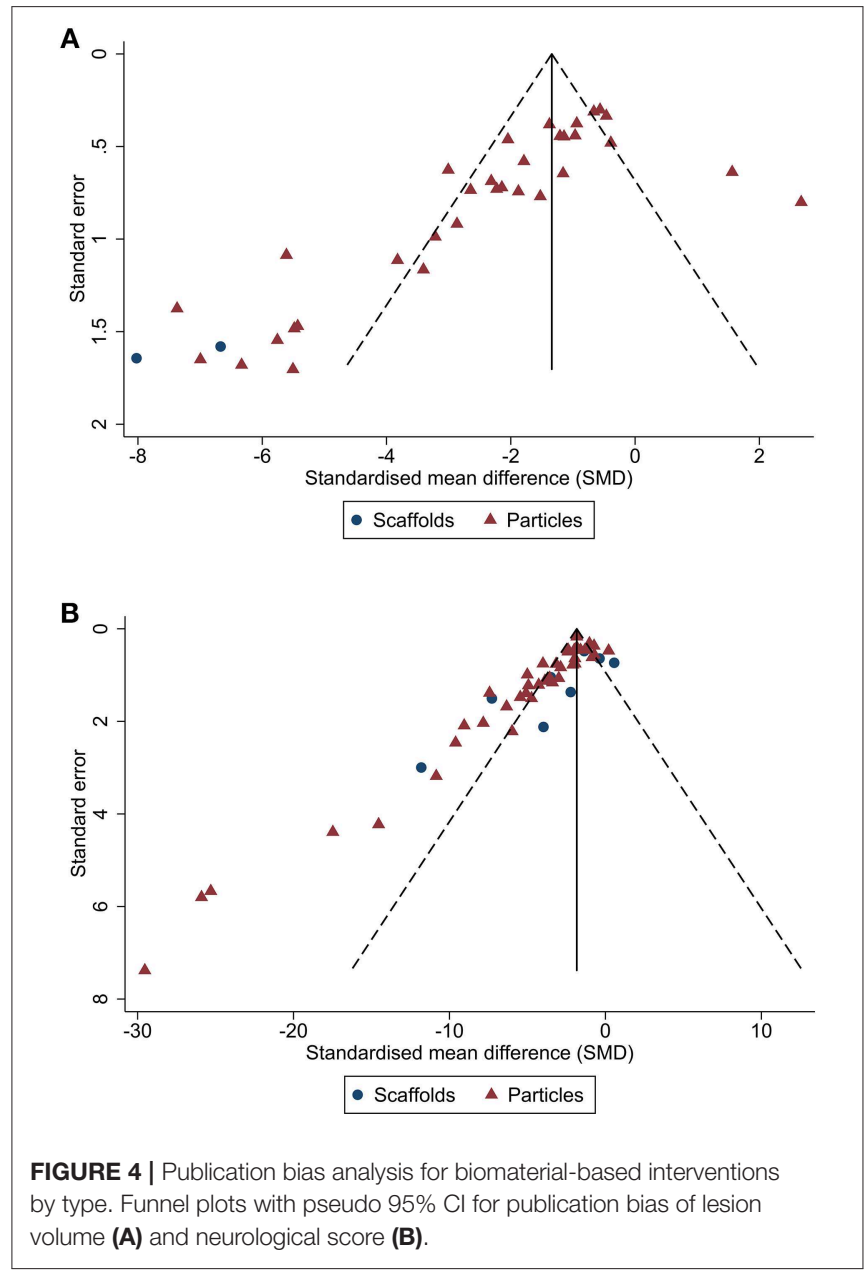

\section{DISCUSSION}

\section{Summary of Findings}

In this study we assessed the efficacy of biomaterial-based approaches in pre-clinical models of ischaemic stroke. A total of 66 publications met our inclusion criteria for the systematic 


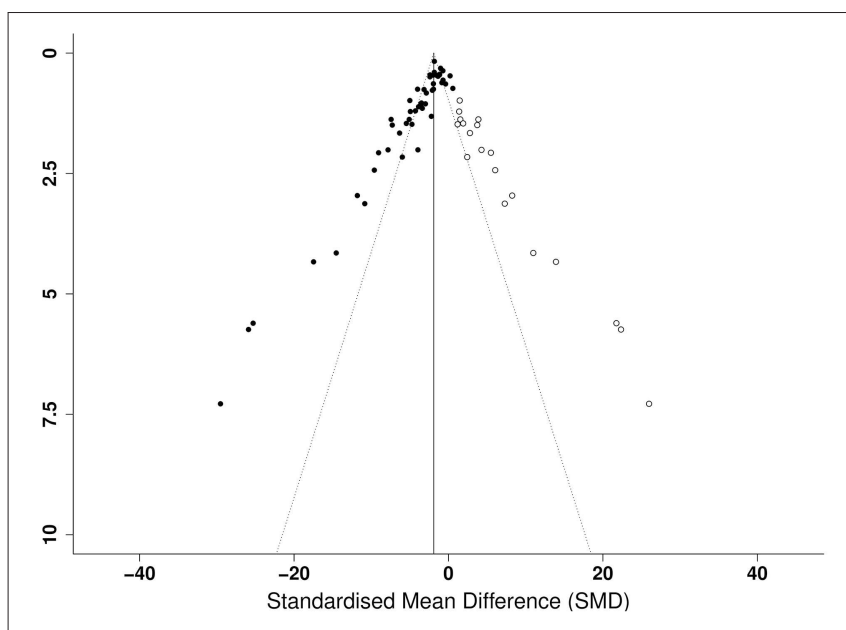

FIGURE 5 | Trim and fill analysis of lesion volume showing published studies (filled circles) and estimated unpublished studies (unfilled circles). The solid vertical line indicates the adjusted effect size.

review with 44 studies (86 comparisons) included in the metaanalysis. Overall, our findings show that biomaterial-based interventions improved both lesion volume and neurological score. Treatment within $24 \mathrm{~h}$ of stroke onset appeared to be the most effective timepoint. We next assessed risk of bias using the CAMARADES checklist (19) and showed the median score was $5.5 / 10$. We also identified pronounced asymmetry in the funnel plots of both the lesion volume and neurological score dataset, indicating publication bias. Trim and fill analysis indicated there were 19 "missing" studies reporting negative or neutral lesion volume data which when adjusted for, greatly reduced the effect size.

\section{Variability in Outcome Measures}

In agreement with a recent systematic review on animal models of stroke and vascular cognitive impairment (29), we reported very high variability in the choice of functional outcome measures. A limitation of the pre-clinical stroke field is the lack of consensus on the optimal test or battery of tests for assessing functional recovery (30). We selected neurological score as one of our outcome measures as it is by far the most widely used assessment of recovery (29). While there are a number of advantages including being fast to perform and requiring no specialist equipment, a large drawback of neurological scores is that they are highly subjective (31). Additionally, we noted there was no standardization in the scale used and a number of publications neglected to report the scoring system used. A further limitation is that as rodents have a great capacity for spontaneous recovery, simpler assessments such as neurological scores often cannot detect deficits at later timepoints (30). These scores may therefore have limited use in studies where scaffold materials are administered at chronic timepoints after stroke (12 weeks) (32-34). In addition, neurological scores are not able to adequately distinguish compensatory strategies from true motor recovery (35) which as previously suggested, could lead to false positives $(36,37)$. Future studies should therefore aim to use tasks such as skilled reaching and gait analysis which can differentiate between the two.

Additionally, we noted that all but two publications identified in our systematic review reported neurological score as mean \pm $\mathrm{SD} / \mathrm{SEM}$. This is surprising given that these data are ordinal and thus should be expressed as median \pm IQR. The calculated effect sizes of individual studies should therefore be approached with caution. Nevertheless, given that the central limit theory states that the mean of a large number of observations will tend toward a normal distribution, our overall effect size for neurological score are robust.

Lesion volume was also chosen as an outcome measure in our meta-analysis given its wide use in the pre-clinical stroke field. The vast majority of the included studies assessing the efficacy of nanoparticles chose acute end points (24-48 h) with lesion volume as the primary outcome measure of neuroprotection. However, most studies assessing the capacity of scaffolds to promote brain regeneration elect to administer during the sub-acute and chronic phase of stroke. In these instances, it is currently unclear whether lesion volume assessment at chronic timepoints is a measure of tissue atrophy, repair or a combination of the two $(33,38,39)$. Future work should therefore focus on developing standardized methods for evaluating tissue regeneration. For example, Ghuman and colleagues have chosen to focus on host cell infiltration into ECM hydrogels as an outcome measure $(32,38)$. Furthermore, it is worth noting that many studies that focused solely on material characterization or assessment of administration at the tissue level were excluded from our systematic review and meta-analysis as lesion volume and neurological scores were not included as outcome measures.

Both histological techniques (including 2,3,5triphenyltetrazolium chloride (TTC), cresyl violet or haematoxylin \& eosin (H\&E) stains) and magnetic resonance imaging (MRI) were used to measure lesion volume. The variation in choice of method likely reflects the availability of MR scanners or preference of researchers toward a certain method. However, this may introduce inter-study variability into lesion volume measurements. A meta-analysis comparing measurements obtained from T2-weighted MR images and histological sections found a strong correlation between the two methods ( $p<0.001)$ (40). Nevertheless, lesion volume measurements from MR images were larger than for histology and there was considerable variation in the reporting and use of MR methods (40). Despite this, as our study compares the SMD of treatment and control group measurements obtained using the same method, the differences in methodology is unlikely to have an effect on the conclusions of our study.

\section{Study Quality and Risk of Bias}

To improve the quality of pre-clinical research, a number of guidelines have been published in recent years including the National Centre for the Replacement, Refinement and Reduction of Animals (NC3Rs) published the Animal Research: Reporting of in vivo Experiments (ARRIVE) guidelines (41). This consists of a checklist of 20 items which should be reported including full details of allocation to experimental groups, sample size calculations and reporting of exact animal numbers. While most 
of the studies included in our systematic review were published after the ARRIVE guidelines (2011 onwards), reporting of these items remained low. This is in agreement with a recent position paper which shows compliance with the guidelines so far has been low (42). We noted that several publications had extremely large effect sizes (SMD >-10) of which a number reported $>80 \%$ reductions in lesion volume following treatment. Previous systematic reviews of in vivo studies have shown that studies reporting the greatest efficacies often have the lowest compliance with such checklists (43). It is possible that limitations in study design could account for an overestimation in effect size and reduced reliability of the results. It has been suggested that the lack of blinding and randomization has led to false positives in neuroprotection studies or over-estimates of efficacy which may have contributed to the translational roadblock in the field (16).

As previously mentioned, our results indicated the presence of publication bias. In particular, trim and fill analysis predicted there was a substantial number of "missing" unpublished studies reporting neutral or negative lesion volume outcomes. Publication bias is an issue not limited to pre-clinical stroke research $(19,44,45)$ which can lead to overestimation of efficacy. For example, a number of studies has shown that conference abstracts reporting positive results are more likely to be published later (46-48). To avoid another translational roadblock, greater emphasis should be placed on publishing negative and neutral data.

\section{Limitations}

This systematic review and meta-analysis is the first to collate the pre-clinical literature on biomaterials for ischaemic stroke. As such, we believe the synthesized findings and conclusions are important for the field. Nevertheless, there are a number of limitations. Firstly, only summary data obtained from the publications was used for the meta-analysis and in many cases, values had to be estimated from graphs. As such, our measurements may differ marginally to the raw values. However, we did not contact authors to obtain these data. A study by the Cochrane Library compared meta-analyses using summary or "aggregate" data to those using raw data and found the difference in results and conclusions to be minimal (49). As our aim was to provide a succinct summary of the current field, we reason that the use of summary data for meta-analysis has negligible impact on the conclusions of the review.

Additionally, the considerable heterogeneity in the types of biomaterials used made identifying suitable subgroups problematic. We reasoned that all of the publications could be classified broadly as either scaffolds (administered at the lesion site for in situ tissue engineering in the sub-acute to chronic phase of stroke) or as particles (usually delivered systemically before or acutely after stroke). We acknowledge the wide range of material types within the chosen subgroups and an alternative option may have been to include a greater number of specific subgroups. However, we reasoned that this would decrease the statistical power of the meta-analysis and the main objective was to give an overview of the efficacy of biomaterial-based approaches in pre-clinical stroke.

We acknowledge our search criteria only identified studies relating to ischaemic stroke. A separate search containing the keywords intracerebral hemorrhage and subarachnoid hemorrhage, returned seven relevant publications (50-56). Based on the small number of publications and the heterogeneity in outcome measures used, we chose not to include these studies. Given our findings concerning risk of bias and study quality, a future systematic review and meta-analysis should investigate this in the emerging field of biomaterial therapies for hemorrhagic stroke.

\section{CONCLUSIONS}

Our meta-analysis revealed that studies assessing biomaterialbased interventions for ischaemic stroke report overall positive results leading to reductions in lesion volume and neurological improvements in rodent models. Additionally, our systematic review regarding study quality showed CAMARADES checklist score was 5.5/10. Our findings provide insight into the field of biomaterials for stroke therapeutics and the quality of studies conducted. We believe the results highlight the need for improved study design and reporting to ultimately support translation of biomaterial-based therapies to the clinical setting.

\section{DATA AVAILABILITY}

All datasets generated for this study are included in the manuscript and/or the Supplementary Files.

\section{AUTHOR CONTRIBUTIONS}

CC: conception. CC, FB, and IL: design, literature search, study screening, data extraction, and manuscript writing. $\mathrm{CH}$ and $\mathrm{CC}$ : data analysis. CC, $\mathrm{CH}, \mathrm{FB}$, and IL: interpretation.

\section{FUNDING}

This work was supported by an Engineering and Physical Sciences Research Council (EPSRC) Doctoral Prize Fellowship grant EP/N509565/1 and EPSRC and Medical Research Council (MRC) Centre for Doctoral Training in Regenerative Medicine studentship grant EP/L014904/1.

\section{ACKNOWLEDGMENTS}

The authors would like to thank Dr. Emily Sena (University of Edinburgh) and Dr. Raymond Wong (University of Manchester) for their advice on data extraction. We would also like to thank Dr. Jack Rivers-Auty (University of Manchester) for his advice on statistical analysis. We also acknowledge the contribution to study design and manuscript editing by Dr. Catherine Lawrence, Dr. Emmanuel Pinteaux, and Prof. Stuart Allan, who are also supervisors of CC, FB, and IL.

\section{SUPPLEMENTARY MATERIAL}

The Supplementary Material for this article can be found online at: https://www.frontiersin.org/articles/10.3389/fneur. 2019.00924/full\#supplementary-material 


\section{REFERENCES}

1. World Health Organisation. Global Status Report on Noncommunicable Diseases 2014. Geneva (2014).

2. Stroke Association. State of the Nation Stroke Statistics. London (2018).

3. Royal College of Physicians Intercollegiate Stroke Working Party. Sentinel Stroke National Audit Programme (SSNAP) Clinical Audit April 2017-July 2017 Public Report. London (2017).

4. Campbell BCV, Mitchell PJ, Kleinig TJ, Dewey HM, Churilov L, Yassi N, et al. Endovascular therapy for ischemic stroke with perfusion-imaging selection. N Engl J Med. (2015) 372:1009-18. doi: 10.1056/NEJMoa1414792

5. Goyal M, Demchuk AM, Menon BK, Eesa M, Rempel JL, Thornton J, et al. Randomized assessment of rapid endovascular treatment of ischemic stroke. N Engl J Med. (2015) 372:1019-30. doi: 10.1056/NEJMoa1414905

6. McMeekin P, White P, James MA, Price CI, Flynn D, Ford GA. Estimating the number of UK stroke patients eligible for endovascular thrombectomy. Eur Stroke J. (2017) 2:319-26. doi: 10.1177/2396987317733343

7. Bhasin A, Kumaran SS, Bhatia R, Mohanty S, Srivastava MVP. Safety and feasibility of autologous mesenchymal stem cell transplantation in chronic stroke in Indian patients. A four-year follow up. J Stem Cells Regen Med. (2017) 13:14-19.

8. Kalladka D, Sinden J, Pollock K, Haig C, McLean J, Smith W, et al. Human neural stem cells in patients with chronic ischaemic stroke (PISCES): a phase 1, first-in-man study. Lancet. (2016) 388:787-96. doi: 10.1016/S0140-6736(16)30513-X

9. Banerjee S, Bentley P, Hamady M, Marley S, Davis J, Shlebak A, et al. Intraarterial immunoselected CD34+ stem cells for acute ischemic stroke. Stem Cells Transl Med. (2014) 3:1322-30. doi: 10.5966/sctm.2013-0178

10. Marquardt LM, Heilshorn SC. Design of injectable materials to improve stem cell transplantation. Curr Stem Cell Rep. (2016) 2:207-20. doi: 10.1007/s40778-016-0058-0

11. Boisserand LSB, Kodama T, Papassin J, Auzely R, Moisan A, Rome C, et al. Biomaterial applications in cell-based therapy in experimental stroke. Stem Cells Int. (2016) 2016:1-14. doi: 10.1155/2016/6810562

12. Tuladhar A, Payne SL, Shoichet MS. Harnessing the potential of biomaterials for brain repair after stroke. Front Mater. (2018) 5:14. doi: 10.3389/fmats.2018.00014

13. Pakulska MM, Ballios BG, Shoichet MS. Injectable hydrogels for central nervous system therapy. Biomed Mater. (2012) 7:24101. doi: 10.1088/1748-6041/7/2/024101

14. Vidu R, Rahman M, Mahmoudi M, Enachescu M, Poteca TD, Opris I. Nanostructures: a platform for brain repair and augmentation. Front Syst Neurosci. (2014) 8:91. doi: 10.3389/fnsys.2014.00091

15. Vieira DB, Gamarra LF. Getting into the brain: liposome-based strategies for effective drug delivery across the blood-brain barrier. Int J Nanomed. (2016) 11:5381-414. doi: 10.2147/IJN.S117210

16. Dirnagl U, Macleod MR. Stroke research at a road block: the streets from adversity should be paved with meta-analysis and good laboratory practice. Br J Pharmacol. (2009) 157:1154-6. doi: 10.1111/j.1476-5381.2009.00211.x

17. Minnerup J, Wersching $H$, Schilling $M$, Schäbitz WR. Analysis of early phase and subsequent phase III stroke studies of neuroprotectants: outcomes and predictors for success. Exp Transl Stroke Med. (2014) 6:2. doi: 10.1186/2040-7378-6-2

18. Chamorro Á, Dirnagl U, Urra X, Planas AM. Neuroprotection in acute stroke: targeting excitotoxicity, oxidative and nitrosative stress, and inflammation. Lancet Neurol. (2016) 15:869-81. doi: 10.1016/S1474-4422(16)00114-9

19. Macleod MR, O'Collins T, Howells DW, Donnan GA. Pooling of animal experimental data reveals influence of study design and publication bias. Stroke. (2004) 35:1203-8. doi: 10.1161/01.STR.0000125719.25853.20

20. George PM, Oh B, Dewi R, Hua T, Cai L, Levinson A, et al. Engineered stem cell mimics to enhance stroke recovery. Biomaterials. (2018) 178:63-72. doi: 10.1016/j.biomaterials.2018.06.010

21. George PM, Bliss TM, Hua T, Lee A, Oh B, Levinson A, et al. Electrical preconditioning of stem cells with a conductive polymer scaffold enhances stroke recovery. Biomaterials. (2017) 142:31-40. doi: 10.1016/j.biomaterials.2017.07.020
22. Saraiva C, Talhada D, Rai A, Ferreira R, Ferreira L, Bernardino L, et al. MicroRNA-124-loaded nanoparticles increase survival and neuronal differentiation of neural stem cells in vitro but do not contribute to stroke outcome in vivo. PLoS ONE. (2018) 13:e0193609. doi: 10.1371/journal.pone.0193609

23. Quittet M-S, Touzani O, Sindji L, Cayon J, Fillesoye F, Toutain J, et al. Effects of mesenchymal stem cell therapy, in association with pharmacologically active microcarriers releasing VEGF, in an ischaemic stroke model in the rat. Acta Biomater. (2015) 15:77-88. doi: 10.1016/j.actbio.2014.12.017

24. Shimbo D, Abumiya T, Kurisu K, Osanai T, Shichinohe H, Nakayama N, et al. Superior microvascular perfusion of infused liposome-encapsulated hemoglobin prior to reductions in infarctions after transient focal cerebral ischemia. J Stroke Cerebrovasc Dis. (2017) 26:2994-3003. doi: 10.1016/j.jstrokecerebrovasdis.2017.07.026

25. Hayon Y, Dashevsky O, Shai E, Brill A, Varon D, Leker RR. Platelet microparticles induce angiogenesis and neurogenesis after cerebral ischemia. Curr Neurovasc Res. (2012) 9:185-92. doi: 10.2174/156720212801 619018

26. Fabian RH, Derry PJ, Rea HC, Dalmeida WV, Nilewski LG, Sikkema WKA, et al. Efficacy of novel carbon nanoparticle antioxidant therapy in a severe model of reversible middle cerebral artery stroke in acutely hyperglycemic rats. Front Neurol. (2018) 9:199. doi: 10.3389/fneur.2018.00199

27. Bederson JB, Pitts LH, Tsuji M, Nishimura MC, Davis RL, Bartkowski H. Rat middle cerebral artery occlusion: evaluation of the model and development of a neurologic examination. Stroke. (1986) 17:472-6. doi: 10.1161/01.STR.17.3.472

28. Longa EZ, Weinstein PR, Carlson S, Cummins R. Reversible middle cerebral artery occlusion without craniectomy in rats. Stroke. (1989) 20:84-91. doi: 10.1161/01.STR.20.1.84

29. Hietamies TM, Ostrowski C, Pei Z, Feng L, McCabe C, Work LM, et al. Variability of functional outcome measures used in animal models of stroke and vascular cognitive impairment - a review of contemporary studies. J Cereb Blood Flow Metab. (2018) 38:1872-84. doi: 10.1177/0271678X18799858

30. Balkaya MG, Trueman RC, Boltze J, Corbett D, Jolkkonen J. Behavioral outcome measures to improve experimental stroke research. Behav Brain Res. (2017)161-71. doi: 10.1016/j.bbr.2017.07.039

31. Schönfeld L-M, Dooley D, Jahanshahi A, Temel Y, Hendrix S. Evaluating rodent motor functions: Which tests to choose? Neurosci Biobehav Rev. (2017) 83:298-312. doi: 10.1016/j.neubiorev.2017.10.021

32. Ghuman H, Mauney C, Donnelly J, Massensini AR, Badylak SF, Modo M. Biodegradation of ECM hydrogel promotes endogenous brain tissue restoration in a rat model of stroke. Acta Biomater. (2018) 80:66-84 doi: 10.1016/j.actbio.2018.09.020

33. Payne SL, Tuladhar A, Obermeyer JM, Varga BV, Teal CI, Morshead $\mathrm{CM}$, et al. Initial cell maturity changes following transplantation in a hyaluronan-based hydrogel and impacts therapeutic success in the stroke-injured rodent brain. Biomaterials. (2019) 192:309-22. doi: 10.1016/j.biomaterials.2018.11.020

34. Cook DJ, Nguyen C, Chun HN, Llorente LI, Chiu AS, Machnicki M, et al. Hydrogel-delivered brain-derived neurotrophic factor promotes tissue repair and recovery after stroke. J Cereb Blood Flow Metab. (2017) 37:103045. doi: 10.1177/0271678X16649964

35. Boltze J, Lukomska B, Jolkkonen J, MEMS-IRBI consortium for the M. Mesenchymal stromal cells in stroke: improvement of motor recovery or functional compensation? J Cereb Blood Flow Metab. (2014) 34:1420-1. doi: $10.1038 / j \mathrm{cbfm} .2014 .94$

36. Cui L, Golubczyk D, Jolkkonen J. Top 3 behavioral tests in cell therapy studies after stroke. Stroke. (2017) 48:3165-7. doi: 10.1161/STROKEAHA.117.018950

37. Hicks A, Schallert T, Jolkkonen J. Cell-based therapies and functional outcome in experimental stroke. Cell Stem Cell. (2009) 5:139-40. doi: 10.1016/j.stem.2009.07.009

38. Ghuman H, Gerwig M, Nicholls FJ, Liu JR, Donnelly J, Badylak SF, et al. Long-term retention of ECM hydrogel after implantation into a subacute stroke cavity reduces lesion volume. Acta Biomater. (2017) 63:50-63. doi: 10.1016/j.actbio.2017.09.011 
39. Sanchez-Rojas L, Gómez-Pinedo U, Benito-Martin MS, León-Espinosa G, Rascón-Ramirez F, Lendinez C, et al. Biohybrids of scaffolding hyaluronic acid biomaterials plus adipose stem cells home local neural stem and endothelial cells: Implications for reconstruction of brain lesions after stroke. J Biomed Mater Res B Appl Biomater. (2018) 107:1598-606 doi: 10.1002/jbm.b.34252

40. Xenios M, Marshall I, Macleod MR, Sena ES. Magnetic resonance imaging in experimental stroke and comparison with histology. Stroke. (2015) 46:84351. doi: 10.1161/STROKEAHA.114.007560

41. Kilkenny C, Browne WJ, Cuthill IC, Emerson M, Altman DG. Improving bioscience research reporting: the ARRIVE guidelines for reporting animal research. PLoS Biol. (2010) 8:e1000412. doi: 10.1371/journal.pbio.1000412

42. Percie du Sert N, Hurst V, Ahluwalia A, Alam S, Altman DG, Avey MT, et al. Revision of the ARRIVE guidelines: rationale and scope. BMJ Open Sci. (2018) 2:e000002. doi: 10.1136/bmjos-2018-000002

43. Macleod MR, Lawson McLean A, Kyriakopoulou A, Serghiou S, de Wilde A, Sherratt $\mathrm{N}$, et al. Risk of bias in reports of in vivo research: a focus for improvement. PLoS Biol. (2015) 13:e1002273. doi: 10.1371/journal.pbio.1002273

44. Landis SC, Amara SG, Asadullah K, Austin CP, Blumenstein R, Bradley EW, et al. A call for transparent reporting to optimize the predictive value of preclinical research. Nat 2012. (2012) 490:187-91. doi: 10.1038/nature11556

45. Sena ES, van der Worp HB, Bath PMW, Howells DW, Macleod MR. Publication bias in reports of animal stroke studies leads to major overstatement of efficacy. PLoS Biol. (2010) 8:e1000344. doi: 10.1371/journal.pbio.1000344

46. Meyer C, Fuller K, Scott J, Vassar M. Is publication bias present in gastroenterological research? An analysis of abstracts presented at an annual congress. PeerJ. (2018) 6:e4995. doi: 10.7717/peerj.4995

47. Callaham ML, Wears RL, Weber EJ, Barton C, Young G. Positive-outcome bias and other limitations in the outcome of research abstracts submitted to a scientific meeting. JAMA. (1998) 280:254-7. doi: 10.1001/jama.280.3.254

48. Scherer RW, Langenberg P, von Elm E. Full publication of results initially presented in abstracts. Cochrane Database Syst Rev. (2007) 2:MR000005. doi: 10.1002/14651858.MR000005.pub3

49. Tudur Smith C, Marcucci M, Nolan SJ, Iorio A, Sudell M, Riley R, et al. Individual participant data meta-analyses compared with meta-analyses based on aggregate data. Cochrane Database Syst Rev. (2016) 9:MR000007. doi: 10.1002/14651858.MR000007.pub3

50. Galho AR, Cordeiro MF, Ribeiro SA, Marques MS, Antunes MFD, Luz DC, et al. Protective role of free and quercetin-loaded nanoemulsion against damage induced by intracerebral haemorrhage in rats. Nanotechnology. (2016) 27:175101. doi: 10.1088/0957-4484/27/17/175101

51. Vaquero J, Otero L, Bonilla C, Aguayo C, Rico MA, Rodriguez A, et al. Cell therapy with bone marrow stromal cells after intracerebral hemorrhage: impact of platelet-rich plasma scaffolds. Cytotherapy. (2013) 15:33-43. doi: 10.1016/j.jcyt.2012.10.005

52. Sang LY-H, Liang Y-X, Li Y, Wong W-M, Tay DK-C, So K-F, et al. A selfassembling nanomaterial reduces acute brain injury and enhances functional recovery in a rat model of intracerebral hemorrhage. Nanomed Nanotechnol Biol Med. (2015) 11:611-20. doi: 10.1016/j.nano.2014.05.012

53. Zhang N, Luo Y, He L, Zhou L, Wu W. A self-assembly peptide nanofibrous scaffold reduces inflammatory response and promotes functional recovery in a mouse model of intracerebral hemorrhage. Nanomed Nanotechnol Biol Med. (2016) 12:1205-17. doi: 10.1016/j.nano.2015.12.387

54. Sakai H, Okamoto M, Ikeda E, Horinouchi H, Kobayashi K, Tsuchida E. Histopathological changes of rat brain after direct injection of $\mathrm{Hb}$-vesicles (artificial oxygen carriers) and neurological impact in an intracerebral hemorrhage model. J Biomed Mater Res Part. (2009) 90A:1107-19. doi: 10.1002/jbm.a.32164

55. Luo $\mathrm{T}$, Guo $\mathrm{T}$, Yang $\mathrm{Q}$, Hao $\mathrm{S}$, Wang $\mathrm{J}$, Cheng $\mathrm{Z}$, et al. In situ hydrogels enhancing postoperative functional recovery by reducing iron overload after intracerebral haemorrhage. Int J Pharm. (2017) 534:179-89. doi: 10.1016/j.ijpharm.2017.10.010

56. Park J, Kim JY, Choi S-K, Kim JY, Kim JH, Jeon WB, et al. Thermosensitive assembly of the biomaterial REP reduces hematoma volume following collagenase-induced intracerebral hemorrhage in rats. Nanomed Nanotechnol Biol Med. (2017) 13:1853-62. doi: 10.1016/j.nano.2017.04.001
57. Hazekawa M, Sakai Y, Yoshida M, Haraguchi T, Uchida T. Single injection of ONO-1301-loaded PLGA microspheres directly after ischaemia reduces ischaemic damage in rats subjected to middle cerebral artery occlusion. J Pharm Pharmacol. (2012) 64:353-359. doi: 10.1111/j.2042-7158.2011.01416.x

58. Marushima A, Suzuki K, Nagasaki Y, Yoshitomi T, Toh K, Tsurushima $\mathrm{H}$, et al. Newly synthesized radical-containing nanoparticles enhance neuroprotection after cerebral ischemia-reperfusion injury. Neurosurgery. (2011) 68:1418-26. doi: 10.1227/NEU.0b013e31820c02d9

59. Nagai N, Yoshioka C, Ito Y, Funakami Y, Nishikawa H, Kawabata A. Intravenous administration of cilostazol nanoparticles ameliorates acute ischemic stroke in a cerebral ischemia/reperfusion-induced injury model. Int J Mol Sci. (2015) 16:29329-44. doi: 10.3390/ijms161226166

60. Jin Q, Cai Y, Li S, Liu H, Zhou X, Lu C, et al. Edaravone-encapsulated agonistic micelles rescue ischemic brain tissue by tuning blood-brain barrier permeability. Theranostics. (2017) 7:884-98. doi: 10.7150/thno. 18219

61. Zhang T, Li C-Y, Jia J-J, Chi J-S, Zhou D, Li J-Z, et al. Combination therapy with LXW7 and ceria nanoparticles protects against acute cerebral ischemia/reperfusion injury in rats. Curr Med Sci. (2018) 38:144-52. doi: 10.1007/s11596-018-1858-5

62. Emerich DF, Silva E, Ali O, Mooney D, Bell W, Yu SJ, et al. Injectable VEGF hydrogels produce near complete neurological and anatomical protection following cerebral ischemia in rats. Cell Transplant. (2010) 19:1063-71. doi: 10.3727/096368910X498278

63. Feczkó T, Piiper A, Ansar S, Blixt FW, Ashtikar M, Schiffmann S, et al. Stimulating brain recovery after stroke using theranostic albumin nanocarriers loaded with nerve growth factor in combination therapy. $J$ Control Release. (2019) 293:63-72. doi: 10.1016/j.jconrel.2018.11.017

64. Moon SU, Kim J, Bokara KK, Kim JY, Khang D, Webster TJ, et al. Carbon nanotubes impregnated with subventricular zone neural progenitor cells promotes recovery from stroke. Int J Nanomed. (2012) 7:2751-65. doi: $10.2147 /$ IJN.S30273

65. Hu J, Huang S, Zhu L, Huang W, Zhao Y, Jin K, et al. Tissue plasminogen activator-porous magnetic microrods for targeted thrombolytic therapy after ischemic stroke. ACS Appl Mater Interfaces. (2018) 10:32988-97. doi: 10.1021/acsami.8b09423

66. Zhang H, Sun F, Wang J, Xie L, Yang C, Pan M, et al. Combining injectable plasma scaffold with mesenchymal stem/stromal cells for repairing infarct cavity after ischemic stroke. Aging Dis. (2017) 8:203-14. doi: 10.14336/AD.2017.0305

67. Lee HJ, Park J, Yoon OJ, Kim HW, Lee DY, Kim DH, et al. Amine-modified single-walled carbon nanotubes protect neurons from injury in a rat stroke model. Nat Nanotechnol. (2011) 6:121-5. doi: 10.1038/nnano.2010.281

68. Hettiaratchi MH, O’Meara MJ, Teal CJ, Payne SL, Pickering AJ, Shoichet MS. Local delivery of stabilized chondroitinase ABC degrades chondroitin sulfate proteoglycans in stroke-injured rat brains. J Control Release. (2019) 297:14-25. doi: 10.1016/j.jconrel.2019.01.033

69. Reddy MK, Labhasetwar V. Nanoparticle-mediated delivery of superoxide dismutase to the brain: an effective strategy to reduce ischemia-reperfusion injury. FASEB J. (2009) 23:1384-95. doi: 10.1096/fj.08-116947

70. Ramos-Cabrer P, Agulla J, Argibay B, Pérez-Mato M, Castillo J. Serial MRI study of the enhanced therapeutic effects of liposomeencapsulated citicoline in cerebral ischemia. Int J Pharm. (2011) 405:228-33. doi: 10.1016/j.ijpharm.2010.12.014

71. Matsuse D, Kitada M, Ogura F, Wakao S, Kohama M, Kira J, et al. Combined transplantation of bone marrow stromal cell-derived neural progenitor cells with a collagen sponge and basic fibroblast growth factor releasing microspheres enhances recovery after cerebral ischemia in rats. Tissue Eng Part A. (2011) 17:1993-2004. doi: 10.1089/ten.tea.2010.0585

72. Liu Y, Ai K, Ji X, Askhatova D, Du R, Lu L, et al. Comprehensive insights into the multi-antioxidative mechanisms of melanin nanoparticles and their application to protect brain from injury in ischemic stroke. JACS. (2017) 139:856-62. doi: 10.1021/jacs.6b11013

73. Fukuta T, Asai T, Sato A, Namba M, Yanagida Y, Kikuchi T, et al. Neuroprotection against cerebral ischemia/reperfusion injury by intravenous administration of liposomal fasudil. Int J Pharm. (2016) 506:129-37. doi: 10.1016/j.ijpharm.2016.04.046 
74. Jin Y-C, Kim S-W, Cheng F, Shin J-H, Park J-K, Lee S, et al. The effect of biodegradable gelatin microspheres on the neuroprotective effects of high mobility group box $1 \mathrm{~A}$ box in the postischemic brain. Biomaterials. (2011) 32:899-908. doi: 10.1016/j.biomaterials.2010.09.054

75. Joachim E, Kim I-D, Jin Y, Kim K, Lee J-K, Choi H. Gelatin nanoparticles enhance the neuroprotective effects of intranasally administered osteopontin in rat ischemic stroke model. Drug Deliv Transl Res. (2014) 4:395-9. doi: 10.1007/s13346-014-0208-9

76. Moshayedi P, Nih LR, Llorente IL, Berg AR, Cinkornpumin J, Lowry WE, et al. Systematic optimization of an engineered hydrogel allows for selective control of human neural stem cell survival and differentiation after transplantation in the stroke brain. Biomaterials. (2016) 105:145-55. doi: 10.1016/j.biomaterials.2016.07.028

77. Ahmad N, Ahmad R, Naqvi AA, Alam MA, Ashafaq M, Abdur Rub R, et al. Intranasal delivery of quercetin-loaded mucoadhesive nanoemulsion for treatment of cerebral ischaemia. Artif Cells Nanomed Biotechnol. (2018) 46:717-29. doi: 10.1080/21691401.2017.1337024

78. Yang $\mathrm{X}, \mathrm{Xu} \mathrm{L}$, Zhou J, Ge Y, Wu S, Huang J, et al. Integration of phospholipid-complex nanocarrier assembly with endogenous $\mathrm{N}$ oleoylethanolamine for efficient stroke therapy. J Nanobiotechnol. (2019) 17:8. doi: 10.1186/s12951-019-0442-x

79. Klose D, Laprais M, Leroux V, Siepmann F, Deprez B, Bordet R, et al. Fenofibrate-loaded PLGA microparticles: effects on ischemic stroke. Eur J Pharm Sci. (2009) 37:43-52. doi: 10.1016/j.ejps.2008.12.016

80. Darabi S, Mohammadi MT. Fullerenol nanoparticles decrease ischaemiainduced brain injury and oedema through inhibition of oxidative damage and aquaporin-1 expression in ischaemic stroke. Brain Inj. (2017) 31:114250. doi: 10.1080/02699052.2017.1300835

81. Harris NM, Ritzel R, Mancini NSN, Jiang Y, Yi X, Manickam DS, et al. Nanoparticle delivery of brain derived neurotrophic factor after focal cerebral ischemia reduces tissue injury and enhances behavioral recovery. Pharmacol Biochem Behav. (2016) 150-151:48-56. doi: 10.1016/j.pbb.2016.09.003

82. Tan L, Liang C, Wang Y, Jiang Y, Zeng S, Tan R. Pharmacodynamic effect of luteolin micelles on alleviating cerebral ischemia reperfusion injury. Pharmaceutics. (2018) 10:E248. doi: 10.3390/pharmaceutics10040248

83. Liu X, An C, Jin P, Liu X, Wang L. Protective effects of cationic bovine serum albumin-conjugated PEGylated tanshinone IIA nanoparticles on cerebral ischemia. Biomaterials. (2013) 34:817-30. doi: 10.1016/j.biomaterials.2012.10.017

84. Bao Q, Hu P, Xu Y, Cheng T, Wei C, Pan L, et al. Simultaneous blood-brain barrier crossing and protection for stroke treatment based on edaravone-loaded ceria nanoparticles. ACS Nano. (2018) 12:6794-805. doi: 10.1021/acsnano.8b01994

85. Bible E, Chau DYS, Alexander MR, Price J, Shakesheff KM, Modo M. The support of neural stem cells transplanted into stroke-induced brain cavities by PLGA particles. Biomaterials. (2009) 30:2985-94. doi: 10.1016/j.biomaterials.2009.02.012

86. Gaudin A, Yemisci M, Eroglu H, Lepetre-Mouelhi S, Turkoglu OF, DönmezDemir B, et al. Squalenoyl adenosine nanoparticles provide neuroprotection after stroke and spinal cord injury. Nat Nanotechnol. (2014) 9:1054-62. doi: $10.1038 /$ nnano.2014.274

87. Ishii T, Asai T, Oyama D, Fukuta T, Yasuda N, Shimizu K, et al. Amelioration of cerebral ischemia-reperfusion injury based on liposomal drug delivery system with asialo-erythropoietin. J Control Release. (2012) 160:81-7. doi: 10.1016/j.jconrel.2012.02.004

88. Wang Y, Cooke MJ, Morshead CM, Shoichet MS. Hydrogel delivery of erythropoietin to the brain for endogenous stem cell stimulation after stroke injury. Biomaterials. (2012) 33:2681-92. doi: 10.1016/j.biomaterials.2011.12.031

89. Ravina K, Briggs DI, Kislal S, Warraich Z, Nguyen T, Lam RK, et al. Intracerebral delivery of brain-derived neurotrophic factor using HyStem ${ }^{\circledR}$-C hydrogel implants improves functional recovery and reduces neuroinflammation in a rat model of ischemic stroke. Int J Mol Sci. (2018) 19:3782. doi: 10.3390/ijms19123782

90. Yan F, Yue W, Zhang Y, Mao G, Gao K, Zuo Z, et al. Chitosancollagen porous scaffold and bone marrow mesenchymal stem cell transplantation for ischemic stroke. Neural Regen Res. (2015) 10:1421-6. doi: $10.4103 / 1673-5374.163466$
91. Guo X, Deng G, Liu J, Zou P, Du F, Liu F, et al. Thrombin-responsive, brain-targeting nanoparticles for improved stroke therapy. ACS Nano. (2018) 12:8723-32. doi: 10.1021/acsnano.8b04787

92. Yu H, Cao B, Feng M, Zhou Q, Sun X, Wu S, et al. Combinated transplantation of neural stem cells and collagen type I promote functional recovery after cerebral ischemia in rats. Anat Rec. (2010) 293:911-7. doi: 10.1002/ar.20941

93. Ahmad N, Ahmad R, Naqvi AA, Alam MA, Ashafaq M, Samim M, et al. Rutin-encapsulated chitosan nanoparticles targeted to the brain in the treatment of Cerebral Ischemia. Int J Biol Macromol. (2016) 91:640-55. doi: 10.1016/j.ijbiomac.2016.06.001

94. Lv W, Xu J, Wang X, Li X, Xu Q, Xin H. Bioengineered boronic ester modified dextran polymer nanoparticles as reactive oxygen species responsive nanocarrier for ischemic stroke treatment. ACS Nano. (2018) 12:5417-26. doi: 10.1021/acsnano.8b00477

95. Liu X, Ye M, An C, Pan L, Ji L. The effect of cationic albumin-conjugated PEGylated tanshinone IIA nanoparticles on neuronal signal pathways and neuroprotection in cerebral ischemia. Biomaterials. (2013) 34:6893-905. doi: 10.1016/j.biomaterials.2013.05.021

96. Yun X, Maximov VD, Yu J, Zhu G, Vertegel AA, Kindy MS. Nanoparticles for targeted delivery of antioxidant enzymes to the brain after cerebral ischemia and reperfusion injury. J Cereb Blood Flow Metab. (2013) 33:58392. doi: 10.1038/jcbfm.2012.209

97. Zhao L, Liu A, Yu S, Wang Z, Lin X, Zhai G, et al. The permeability of puerarin loaded poly(butylcyanoacrylate) nanoparticles coated with polysorbate 80 on the blood-brain barrier and its protective effect against cerebral ischemia/reperfusion injury. Biol Pharm Bull. (2013) 36:1263-70. doi: 10.1248/bpb.b12-00769

98. Jin Y, Kim I-Y, Kim I-D, Lee H-K, Park J-Y, Han P-L, et al. Biodegradable gelatin microspheres enhance the neuroprotective potency of osteopontin via quick and sustained release in the post-ischemic brain. Acta Biomater. (2014) 10:3126-35. doi: 10.1016/j.actbio.2014.02.045

99. Chen S-J, Chang C-M, Tsai S-K, Chang Y-L, Chou S-J, Huang S-S, et al. Functional improvement of focal cerebral ischemia injury by subdural transplantation of induced pluripotent stem cells with fibrin glue. Stem Cells Dev. (2010) 19:1757-67. doi: 10.1089/scd.2009.0452

100. Nih LR, Gojgini S, Carmichael ST, Segura T. Dual-function injectable angiogenic biomaterial for the repair of brain tissue following stroke. Nat Mater. (2018) 17:642-51. doi: 10.1038/s41563-018-0083-8

101. Hassanzadeh P, Atyabi F, Dinarvand R, Dehpour A-R, Azhdarzadeh M, Dinarvand M. Application of nanostructured lipid carriers: the prolonged protective effects for sesamol in in vitro and in vivo models of ischemic stroke via activation of PI3K signalling pathway. DARU J Pharm Sci. (2017) 25:25. doi: 10.1186/s40199-017-0191-z

102. Parent M, Boudier A, Perrin J, Vigneron C, Maincent P, Violle N, et al. In situ microparticles loaded with S-nitrosoglutathione protect from stroke. PLoS ONE. (2015) 10:e0144659. doi: 10.1371/journal.pone.0144659

103. Jin K, Mao X, Xie L, Galvan V, Lai B, Wang Y, et al. Transplantation of human neural precursor cells in matrigel scaffolding improves outcome from focal cerebral ischemia after delayed postischemic treatment in rats. J Cereb Blood Flow Metab. (2010) 30:534-44. doi: 10.1038/jcbfm.2009.219

104. Mdzinarishvili A, Sutariya V, Talasila PK, Geldenhuys WJ, Sadana P. Engineering triiodothyronine (T3) nanoparticle for use in ischemic brain stroke. Drug Deliv Transl Res. (2013) 3:309-17. doi: 10.1007/s13346-012-0117-8

105. Vani JR, Mohammadi MT, Foroshani MS, Jafari M. Polyhydroxylated fullerene nanoparticles attenuate brain infarction and oxidative stress in rat model of ischemic stroke. EXCLI J. (2016) 15:378-90. doi: 10.17179/excli2016-309

106. Takamiya M, Miyamoto Y, Yamashita T, Deguchi K, Ohta Y, Abe K. Strong neuroprotection with a novel platinum nanoparticle against ischemic stroke- and tissue plasminogen activator-related brain damages in mice. Neuroscience. (2012) 221:47-55. doi: 10.1016/j.neuroscience.2012. 06.060

107. Ahmad N, Ahmad R, Abbas Naqvi A, Ashafaq M, Alam MA, Ahmad FJ, et al. The effect of safranal loaded mucoadhesive nanoemulsion on oxidative stress markers in cerebral ischemia. Artif Cells Nanomed Biotechnol. (2017) 45:775-87. doi: 10.1080/21691401.2016.1228659 
108. Sarami Foroshani M, Sobhani ZS, Mohammadi MT, Aryafar M. Fullerenol nanoparticles decrease blood-brain barrier interruption and brain edema during cerebral ischemiareperfusion injury probably by reduction of interleukin-6 and matrix metalloproteinase-9 transcription. J Stroke Cerebrovasc Dis. (2018) 27:3053-65. doi: 10.1016/j.jstrokecerebrovasdis.2018. 06.042

109. Wang Y, Li S-Y, Shen S, Wang J. Protecting neurons from cerebral ischemia/reperfusion injury via nanoparticle-mediated delivery of an siRNA to inhibit microglial neurotoxicity. Biomaterials. (2018) 161:95-105. doi: 10.1016/j.biomaterials.2018. 01.039

110. Wang Z, Zhao Y, Jiang Y, Lv W, Wu L, Wang B, et al. Enhanced antiischemic stroke of ZL006 by T7-conjugated PEGylated liposomes drug delivery system. Sci Rep. (2015) 5:12651. doi: 10.1038/srep 12651

Conflict of Interest Statement: The authors declare that the research was conducted in the absence of any commercial or financial relationships that could be construed as a potential conflict of interest.

Copyright (c) 2019 Bolan, Louca, Heal and Cunningham. This is an open-access article distributed under the terms of the Creative Commons Attribution License (CC $B Y)$. The use, distribution or reproduction in other forums is permitted, provided the original author(s) and the copyright owner(s) are credited and that the original publication in this journal is cited, in accordance with accepted academic practice. No use, distribution or reproduction is permitted which does not comply with these terms. 